\title{
Health care resource utilization before and after natalizumab initiation among patients with multiple sclerosis in Germany
}

This article was published in the following Dove Press journal:

ClinicoEconomics and Outcomes Research

I February 2017

Number of times this article has been viewed

\section{Crystal Watson' \\ Christine Prosser ${ }^{2}$ \\ Sebastian Braun ${ }^{2}$ \\ Pamela B \\ Landsman-Blumberg ${ }^{3}$ \\ Erika Gleissner ${ }^{4}$ \\ Sarah Naoshy'}

'Health Economics and Outcomes Research, Global Market Access, Biogen, Cambridge, MA, USA; ${ }^{2}$ Real World Evidence, Xcenda GmbH, Hanover, Germany; ${ }^{3}$ Applied Data Analytics, Xcenda LLC, Palm Harbor, FL, USA; ${ }^{4}$ Market Access, Biogen, Ismaning, Germany
Correspondence: Crystal Watson Health Economics and Outcomes Research, Global Market Access, Biogen, 225 Binney St., Cambridge, MA 02142, USA

Tel + I 78I 4645613

Fax + I $86626 \mid 2808$

Email crystal.watson@biogen.com
Background: Multiple sclerosis (MS), a progressive neurodegenerative disease, greatly impacts the quality of life and economic status of people affected by this disease. In Germany, the total annual cost of MS is estimated at $€ 40,000$ per person with MS. Natalizumab has shown to slow MS disease progression, reduce relapses, and improve the quality of life of people with MS.

Objective: To evaluate MS-related and all-cause health care resource utilization and costs among German MS patients during the 12 months before and after initiation of natalizumab in a real-world setting.

Methods: The current analysis was conducted using the Health Risk Institute research database. Identified patients were aged $\geq 18$ years with $\geq 1$ diagnosis of MS and had initiated natalizumab therapy (index), with 12-month pre- and post-index-period data. Patients were stratified by prior disease-modifying therapy (DMT) usage or no DMT usage in the pre-index period. Outcome measures included corticosteroid use and number of sick/disability days, inpatient stays, and outpatient visits. Health care costs were calculated separately for pre- and post-index periods on a per-patient basis and adjusted for inflation.

Results: In a final sample of 193 natalizumab-treated patients, per-patient MS-related corticosteroid use was reduced by $62.3 \%$, MS-related sick days by $27.6 \%$, and inpatient costs by $78.3 \%$ from the pre- to post-index period. Furthermore, the proportion of patients with MS-related hospitalizations decreased from $49.7 \%$ to $14.0 \%(P<0.001)$; this reduction was seen for patients with and without prior DMT use.

Conclusions: In a real-world setting in Germany, initiation of natalizumab treatment in people with MS significantly reduced MS-related hospitalizations, corticosteroid use, sick days, and associated costs.

Keywords: multiple sclerosis, relapsing-remitting, health care resource utilization, costs, outcomes, natalizumab

\section{Introduction}

Multiple sclerosis (MS) is a progressive, degenerative disease of the central nervous system, characterized by multiple symptoms, including spasticity; problems with walking, balance, and coordination; fatigue, depression, and mood disorders; bladder, bowel, and sexual dysfunction; and cognitive impairment. As such, MS is the leading cause of disability among nonelderly individuals in industrialized countries. ${ }^{1}$ In Germany, it is estimated that at least 120,000 people have $\mathrm{MS},{ }^{2}$ with the total annual cost of MS in Germany estimated to be $€ 40,000$ per person with MS. ${ }^{3,4}$ MS pathogenesis is characterized by inflammatory and neurodegenerative mechanisms, ${ }^{5}$ which manifest as relapses ${ }^{6,7}$ and disability progression, ${ }^{8}$ respectively. 
The most common form of MS is relapsing-remitting MS (RRMS), whereby an unpredictable course of relapses is followed by a period of remission and recovery. ${ }^{9} \mathrm{MS}$ relapses have been shown to profoundly affect an individual's quality of life, as occurrences interfere with the ability to perform daily activities, are linked to emotional distress and depression, and impact family, friends, and caregivers. ${ }^{10}$ Thus, the societal, economic, familial, and personal burden of MS relapses is enormous.

People with MS who experience relapses are often treated with corticosteroids and admitted to the hospital. ${ }^{11}$ MS relapses contribute significantly to the costs associated with the disease, ${ }^{12}$ which increase with disease severity. ${ }^{12-14}$

Treatments that can slow or prevent the progression of MS have the potential to significantly improve the quality of life for people with MS and reduce the economic impact of the disease. ${ }^{14,15}$ Natalizumab, a selective adhesion-molecule inhibitor, has been shown to reduce annualized relapse rates by $68 \%$ versus placebo among people with $\mathrm{RRMS}^{16,17}$ and by $81 \%$ versus placebo among people with highly active RRMS. ${ }^{18}$ In the European Union, natalizumab is indicated in adults with highly active RRMS who failed to respond to an adequate course of interferon beta or glatiramer acetate, and in adults with rapidly evolving severe RRMS (with $\geq 2$ relapses in 1 year and $\geq 1$ gadolinium-enhancing lesion or a significant increase in $\mathrm{T} 2$ lesion load compared with a previous recent magnetic resonance imaging assessment). ${ }^{19}$

In Germany, $\sim 90 \%$ of the population ( $\sim 70$ million individuals) is insured as part of the Statutory Health Insurance (SHI) program, ${ }^{20,21}$ and the prevalence of MS among people insured by the SHI in 2010 was estimated to range from 120,000 to $\geq 200,000 .{ }^{22}$ The objective of this study was to evaluate MS-related and all-cause health care resource utilization (HRU) and costs among German people with MS during the 12 months before and 12 months after initiation of natalizumab in a real-world setting. In addition, HRU and costs were evaluated after stratifying people with MS by whether or not they had used a disease-modifying therapy (DMT) during the pre-index period. Although several studies have evaluated the economic burden of MS in Germany, ${ }^{3,4,15}$ to our knowledge this is the first study to evaluate MS-related HRU and costs among natalizumab-treated people with MS based on their previous DMT exposure.

\section{Methods}

\section{Database}

The current analysis was conducted using the Health Risk Institute (HRI) research database, which contains anonymized, patient-level inpatient, outpatient, sick leave, and pharmacy claims data from about 80 health insurance companies, representing a high proportion of the $\sim 130$ health insurance companies that comprise the SHI in Germany ${ }^{20}$ and providing good external validity. ${ }^{23}$ For 2008-2013, the HRI research database contained individual, de-identified claims data for about 4 million people, with a patient sample that is representative of the German population for age and gender. ${ }^{24,25}$ The database is fully compliant with all data protection regulations in Germany and has been certified. As the HRI research database includes verified accounting data of the participating insurance companies, these claims data are regularly audited by the insurance companies for reimbursement purposes and are prepared in accordance with German Social Law (paragraphs 287 SGB V and 75 SGB X). This study utilized an existing data set in line with all data protection regulations, and patients were not identified for the purpose of this study.

This study is a retrospective database study based on fully anonymized claims data, and claims data are recorded for accounting purposes and not for clinical research. No electronic medical records or other clinical parameters were used. As a result, no ethical approval or consent from an ethics committee or review board was required for this study.

\section{Case selection}

The study sample included patients aged $\geq 18$ years who initiated treatment with natalizumab (index date [Anatomical Therapeutic Chemical \{ATC\} code L04AA23] between January 1, 2009, and December 31, 2012). All patients had a primary or secondary diagnosis of MS (International Statistical Classification of Diseases and Related Health Problems, 10th revision, German Modification [ICD-10-GM] codes G35.xx) in the inpatient sector in the pre-index period or a verified diagnosis of MS in the outpatient sector during any of the four quarters before the index quarter. At least 24 months of continuous eligibility was required, including a 12-month pre-index period and a 12-month post-index period. Furthermore, patients had to have $\geq 1$ natalizumab prescription in the fourth quarter of the post-index period to indicate continuous natalizumab use. Thus, the entire study covered the time interval from January 1,2008, to December 31, 2013 (Figure 1).

\section{Patient groups}

Outcomes were evaluated in the overall sample of patients who initiated treatment with natalizumab and in natalizumab 


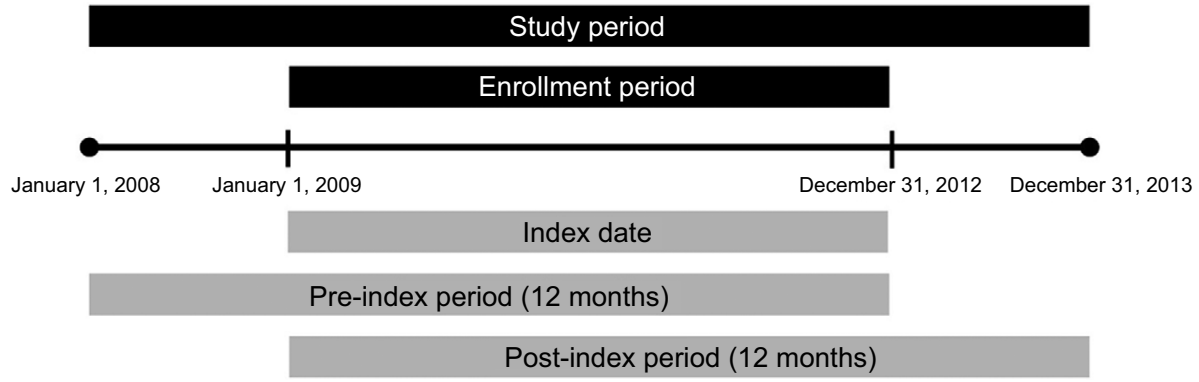

Figure I Study design.

initiators based on the prior use of other DMTs. Patients were categorized as having used (prior DMT use) or not used (no prior DMT use) another DMT during the 12-month pre-index period.

\section{Outcome measures}

Patient demographic and clinical characteristics included age, gender, and index year. The Deyo-Charlson Comorbidity Index (DCI), ${ }^{26,27}$ a summary measure of comorbidity burden, is reported as both a continuous and categorical measure. Individual DCI comorbidities are reported as binary outcomes (i.e., present or not present). MS-related and all-cause hospitalizations were defined as having a primary MS-related ICD-10-GM code (G35.xx) or any ICD-10-GM code, respectively. For the total population, the total number of inpatient stays and total length of stay were each summed across all admissions for the pre- and post-index period.

The use of corticosteroids (intravenous [IV] and oral) was determined if a patient had $\geq 1$ prescription claim for dexamethasone, methylprednisolone, prednisolone, prednisone, or adrenocorticotropic hormone. Similarly, immunosuppressant use was recorded affirmatively if a patient had $\geq 1$ claim for an immunosuppressant. Per the German Association of Neurologists' guidelines for diagnosis and treatment of MS, ${ }^{28}$ drugs for MS symptom relief include antidementia agents, antidepressants, antiepileptics, muscle relaxants (i.e., baclofen, botulinum toxin, dantrolene, tizanidine, tolperisone, and tetrazepam), antispasmodics, and select medications to manage fatigue (i.e., amantadine and modafinil), tremor (i.e., propranolol), and sexual dysfunction (i.e., sildenafil, tadalafil, and tibolone). Use of MS symptom relief and all MS-related prescription medications was identified using the ATC classification system.

Health care-related costs (in Euros $[€]$ ) were calculated separately for the pre- and post-index periods on a per-patient basis and converted to $2013 €$ using the general rate of inflation for Germany. ${ }^{29}$ MS-related inpatient costs were defined as the total costs for patient hospitalizations with a primary
ICD-10-GM code for MS, and all-cause costs were defined as the total costs for admissions for any reason. Total costs for corticosteroids (IV, oral, and self-injectable) and immunosuppressants were summed across all relevant prescription claims. Total costs for MS-related outcomes were calculated as the sum of all costs for MS-related hospitalizations, corticosteroids, and immunosuppressants. Costs were collected in the HRI database and the reported costs were those for which the SHIs pay. In the inpatient sector, a German diagnosisrelated group system was used.

Additional end points included the percentage of patients having any sick or disability days (sick leave $>6$ weeks), the number of MS-related and all-cause sick days, and all-cause disability days.

\section{Statistical analyses}

Results for baseline demographic and clinical characteristics, HRU and costs, and sick days and disability days are summarized descriptively. Continuous variables are presented as means (with standard deviations [SDs]) or medians (with ranges), depending on the distributions of the data. Categorical variables are presented as frequency distributions and percentages. Statistical comparisons of baseline demographic and clinical characteristics between those with and without prior DMT use were performed using nonpaired $t$-tests for means and Mann-Whitney $U$ tests for medians; chi-square and Fisher's exact tests were used for comparisons of proportions.

Statistical comparisons of the changes from the pre- to post-index period for HRU, costs, sick days, and disability days were performed using one-sample $t$-tests for means and Wilcoxon signed-rank tests for medians; McNemar chi-square tests were used for comparisons of categorical data. Statistical comparisons of the changes from the pre- to post-index period between patients with and without prior DMT use were performed using Two-sample $t$-tests for means and Wilcoxon rank-sum tests for medians; Mantel-Haenszel chi-square tests were used for categorical data. 


\section{Results}

\section{Patient disposition and characteristics}

The final sample included 193 patients who initiated treatment with natalizumab between 2009 and 2012 and met all selection criteria (Figure 2). The majority of patients (75\%; $n=145$ ) had used another DMT during the pre-index period. The mean (SD) age was 37.1 (10.2) years, and 65\% of the sample was female. Overall, hemiplegia or paraplegia (20.7\%) and chronic pulmonary disease (19.7\%) were the most prevalent conditions contributing to the DCI. With the exception of mean DCI, which was significantly higher among patients with prior DMT use, baseline demographic and clinical characteristics were comparable regardless of prior DMT use (Table 1).

\section{Inpatient hospitalizations and expenditures}

MS-related and all-cause inpatient HRU and expenditures were reduced after initiating natalizumab compared with the pre-index period. In the overall sample, the proportion of patients with MS-related hospitalizations decreased significantly on natalizumab therapy, from $49.7 \%$ to $14.0 \%$ $(P<0.001$; Figure $3 \mathrm{~A})$, with a corresponding decrease in the per-patient mean number of MS-related hospitalizations from 1.1 to 0.2 ( $P<0.001$; Table 2$)$. The mean number of MS-related inpatient days among those with hospital stays decreased by $61.3 \%$, from 7.0 days $(\mathrm{n}=96)$ in the pre-index period to $2.7(\mathrm{n}=27)$ on natalizumab therapy $(P<0.001$; Table 2).

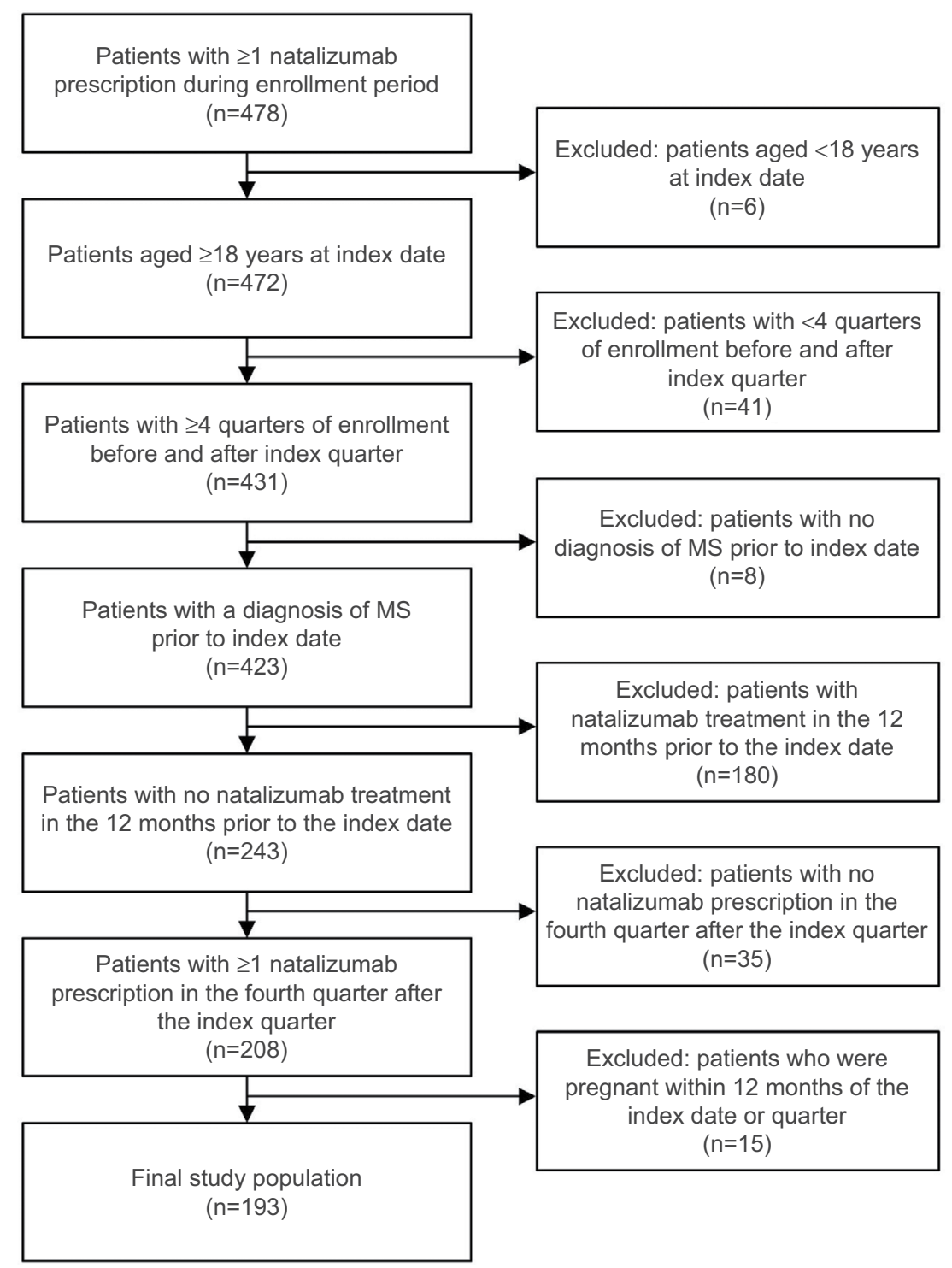

Figure 2 Patient selection process. Abbreviation: MS, multiple sclerosis. 
Table I Baseline demographic and clinical characteristics of patients initiating treatment with natalizumab

\begin{tabular}{|c|c|c|c|c|}
\hline Characteristic & $\begin{array}{l}\text { All patients } \\
(\mathrm{N}=193)\end{array}$ & $\begin{array}{l}\text { With prior } \\
\text { DMT use }(n=145)\end{array}$ & $\begin{array}{l}\text { Without prior } \\
\text { DMT use }(n=48)\end{array}$ & $P$-value ${ }^{\mathrm{a}}$ \\
\hline \multicolumn{5}{|l|}{ Age, years } \\
\hline Mean (SD) & $37.1(10.2)$ & $37.1(9.8)$ & $37.1(11.4)$ & 0.818 \\
\hline Median (range) & $37(19,61)$ & $38(19,60)$ & $36(2 I, 6 I)$ & \\
\hline Female gender, n (\%) & $125(64.8)$ & $91(62.8)$ & $34(70.8)$ & 0.384 \\
\hline \multicolumn{5}{|l|}{ Index year, n (\%) } \\
\hline 2009 & $37(19.2)$ & $26(17.9)$ & II (22.9) & 0.747 \\
\hline 2010 & $39(20.2)$ & $30(20.7)$ & $9(18.8)$ & \\
\hline 2011 & $55(28.5)$ & $40(27.6)$ & $15(31.3)$ & \\
\hline 2012 & $62(32.1)$ & $49(33.8)$ & $13(27.1)$ & \\
\hline \multicolumn{5}{|l|}{ DCI score } \\
\hline Mean (SD) & $0.88(\mathrm{I} .2)$ & $0.99(1.3)$ & $0.54(0.9)$ & 0.031 \\
\hline Median (range) & $0(0.0,5.0)$ & $0(0.0,5.0)$ & $0(0.0,3.0)$ & \\
\hline \multicolumn{5}{|l|}{ DCl conditions $\geq 5 \%, n(\%)$} \\
\hline Hemiplegia or paraplegia & $40(20.7)$ & $34(23.4)$ & $6(12.5)$ & 0.149 \\
\hline Chronic pulmonary disease & $38(19.7)$ & $31(21.4)$ & $7(14.6)$ & 0.403 \\
\hline Diabetes without complications & $12(6.2)$ & $10(6.9)$ & $2(4.2)$ & 0.733 \\
\hline Mild liver disease & II (5.7) & $9(6.2)$ & $2(4.2)$ & 0.734 \\
\hline \multicolumn{5}{|l|}{ Prior DMT, n (\%) } \\
\hline Glatiramer acetate $\left(\right.$ Copaxone $\left.{ }^{\circledR}\right)$ & $42(21.8)$ & $42(29.0)$ & $0(0.0)$ & Not applicable \\
\hline Intramuscular interferon beta-Ia $\left(\right.$ Avonex $\left.^{\circledR}\right)$ & $34(17.6)$ & $34(23.4)$ & $0(0.0)$ & \\
\hline SC interferon beta- Ib (Betaferon $\left.{ }^{\circledR}\right)$ & $28(14.5)$ & $28(19.3)$ & $0(0.0)$ & \\
\hline SC interferon beta-la $\left(\right.$ Rebif $\left.^{\circledR}\right)$ & $28(14.5)$ & $28(19.3)$ & $0(0.0)$ & \\
\hline SC interferon beta-Ib (Extavia $\left.{ }^{\circledR}\right)$ & $7(3.6)$ & $7(4.8)$ & $0(0.0)$ & \\
\hline Fingolimod $\left(\right.$ Gilenya $\left.{ }^{\circledR}\right)$ & $6(3.1)$ & $6(4.1)$ & $0(0.0)$ & \\
\hline No prior DMT & $48(24.9)$ & $0(0.0)$ & $48(100)$ & \\
\hline \multicolumn{5}{|l|}{ Multiple sclerosis-related medications, n (\%) } \\
\hline Corticosteroids ${ }^{\mathrm{b}}$ & $146(75.6)$ & $116(80.0)$ & $30(62.5)$ & 0.020 \\
\hline Immunosuppressants & $10(5.2)$ & $7(4.8)$ & $3(6.3)$ & 0.712 \\
\hline
\end{tabular}

Notes: ap values for the comparison of the subgroups of patients with and without prior DMT use; bdexamethasone, methylprednisolone, prednisolone, prednisone, or adrenocorticotropic hormone.

Abbreviations: DCI, Deyo-Charlson comorbidity index; DMT, disease-modifying therapy; SC, subcutaneous; SD, standard deviation.

In the overall sample, the proportion of patients with MS-related hospitalizations decreased by $71.8 \%$ while on natalizumab therapy $(P<0.001$; Figure $3 \mathrm{~A})$. Similarly significant reductions were observed for patients with $(70.2 \%$, $P<0.001)$ and without $(77.3 \%, P<0.001)$ prior DMT use. The mean number of MS-related hospitalizations also decreased significantly in both groups, from 1.1 to 0.2 in patients with prior DMT use $(P<0.001)$ and from 0.9 to 0.1 in patients without prior DMT use $(P<0.001$; Table S1). Among all MS patients, the mean duration of hospital stays decreased by $52.8 \%$ in patients with prior DMT use (from 7.2 to 3.4 days; $P<0.001)$ and by $90.5 \%$ in patients without prior DMT use (from 6.3 to 0.6 days; $P<0.001$ ).

Mean annual per-patient MS-related inpatient costs decreased by $78.3 \%$, from $€ 3,759$ (median, $€ 706$; range, $€ 0-€ 60,583$ ) in the pre-index period to $€ 815$ (median, $€ 0$; range, $€ 0-€ 25,934$ ) in the post-index period in the overall sample, and by $76.6 \%$ and $83.9 \%$ in patients with and without prior DMT use, respectively (all $P<0.001$; Figure 3B).
In the overall sample, the proportion of patients hospitalized for any cause decreased by $52.4 \%$ while on natalizumab therapy $(P<0.001$; Figure $4 \mathrm{~A})$. The mean number of all-cause hospitalizations was 1.3 in the pre-index period and 0.4 in the post-index period $(P<0.001)$, and the mean duration of these stays decreased by $48.2 \%$, from 9.6 to 5.0 days $(P<0.001$; Table 2). Similar reductions after natalizumab initiation were observed in the subgroups of patients with and without prior DMT use (Figure 4A; Table S1).

Mean annual per-patient all-cause inpatient costs decreased by $64.0 \%$, from $€ 4,610$ (median, $€ 2,365$; range, $€ 0 € € 60,583$ ) in the pre-index period to $€ 1,660$ (median, $€ 0$; range, $€ 0-€ 33,719)$ in the post-index period in the overall sample and by $58.9 \%$ and $78.7 \%$ in patients with and without prior DMT use, respectively (all $P<0.001$; Figure 4B).

\section{Corticosteroid use}

In the first year of treatment with natalizumab, statistically significant reductions from the pre-index period in the 

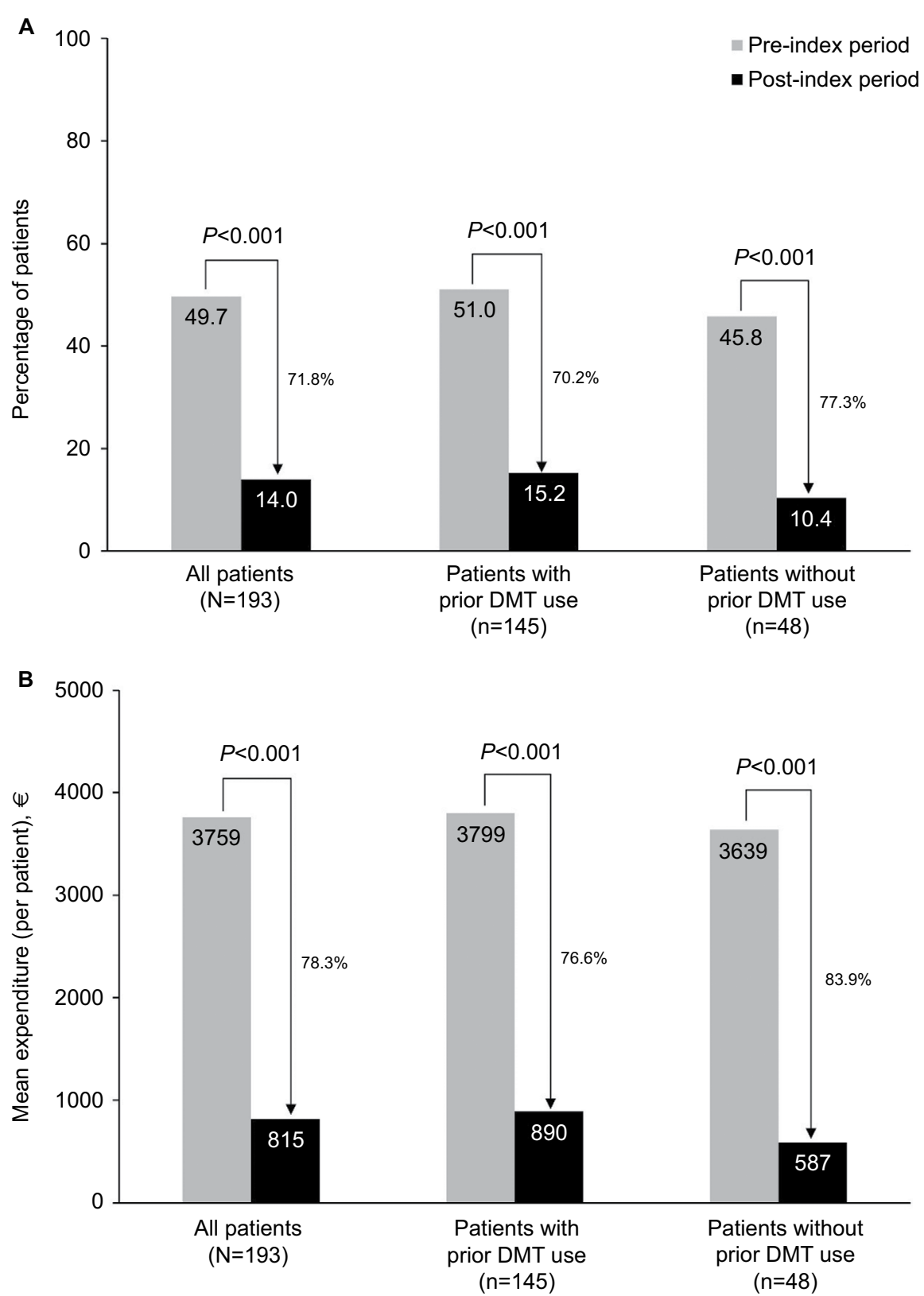

Figure 3 Multiple sclerosis-related (A) hospitalizations and (B) inpatient costs. Abbreviation: DMT, disease-modifying therapy.

proportions of patients using corticosteroids were observed among all patients (62.3\% reduction) and among those with (63.8\% reduction) and without (56.6\% reduction) prior DMT use (all $P<0.001$; Figure 5A). Similarly, a significant decrease was observed in the mean number of corticosteroid prescriptions for all patients (from 2.4 to $0.6 ; P<0.001$ ). Patients who had received prior DMTs showed a larger change in corticosteroid use (from 2.6 to 0.6 ) than those who did not receive prior DMTs (from 2.1 to 0.9 ; all $P<0.001$; Table 2; Table S1). Mean expenditures associated with corticosteroid use also significantly declined in each patient group (decreased by $78.9 \%, 79.0 \%$, and $78.2 \%$ for patients overall, with prior
DMT use, and without prior DMT use, respectively; all $P<0.001$; Figure 5B).

\section{Sick days and disability days}

After initiation of natalizumab, the percentage of patients with MS-related and all-cause sick days decreased from the pre-index period by $27.6 \%(P<0.001)$ and $14.0 \%(P=0.011)$, respectively (Figure 6A, B). The percentages of patients with sick days also decreased in patients with and without prior DMT use; however, only the changes in the former group were statistically significant (Figure 6A, B). In contrast, changes in the mean number of MS-related and all-cause sick 
Table 2 Health care resource utilization among overall patient sample before and after initiating treatment with natalizumab

\begin{tabular}{|c|c|c|c|c|}
\hline \multirow{2}{*}{$\begin{array}{l}\text { Health care } \\
\text { resource utilization }\end{array}$} & \multicolumn{4}{|c|}{ All patients $(\mathrm{N}=193)$} \\
\hline & Pre-index & Post-index & Change & $P$-value \\
\hline \multicolumn{5}{|c|}{ Number of hospitalizations } \\
\hline \multicolumn{5}{|c|}{ MS-related } \\
\hline Mean (SD) & I.I (I.5) & $0.2(0.7)$ & $-0.9(1.4)$ & $<0.001$ \\
\hline Median (range) & $0(0,8)$ & $0(0,5)$ & $0(-6,3)$ & \\
\hline \multicolumn{5}{|l|}{ All-cause } \\
\hline Mean (SD) & I.3 (I.8) & $0.4(I . I)$ & $-0.9(1.8)$ & $<0.001$ \\
\hline Median (range) & $\mathrm{I}(0,9)$ & $0(0,11)$ & $0(-8,9)$ & \\
\hline \multicolumn{5}{|c|}{ Number of inpatient days } \\
\hline \multicolumn{5}{|c|}{ MS-related } \\
\hline Mean (SD) & $7.0(10.7)$ & $2.7(20.5)$ & $-4.3(20.5)$ & $<0.001$ \\
\hline Median (range) & $0(0,62)$ & $0(0,277)$ & $0(-62,238)$ & \\
\hline \multicolumn{5}{|l|}{ All-cause } \\
\hline Mean (SD) & $9.6(16.6)$ & $5.0(23.5)$ & $-4.6(25.0)$ & $<0.001$ \\
\hline Median (range) & $4(0,113)$ & $0(0,277)$ & $0(-113,238)$ & \\
\hline \multicolumn{5}{|l|}{ Corticosteroid use } \\
\hline Mean (SD) & $2.4(2.5)$ & $0.6(1.3)$ & $-1.8(2.4)$ & $<0.001$ \\
\hline Median (range) & $2(0,19)$ & $0(0,8)$ & $-1(-19,3)$ & \\
\hline \multicolumn{5}{|l|}{ Number of sick days } \\
\hline \multicolumn{5}{|l|}{ MS-related } \\
\hline Mean (SD) & $29.8(53.1)$ & $21.8(55.8)$ & $-8.0(59.7)$ & $<0.001$ \\
\hline Median (range) & $\mathrm{I}(0,326)$ & $0(0,366)$ & $0(-308,311)$ & \\
\hline \multicolumn{5}{|l|}{ All-cause } \\
\hline Mean (SD) & $36.2(58.5)$ & $27.9(6 I .4)$ & $-8.3(63.8)$ & $<0.001$ \\
\hline Median (range) & $5(0,330)$ & $0(0,366)$ & $0(-3 \mid 2,256)$ & \\
\hline \multicolumn{5}{|c|}{ Number of all-cause disability days } \\
\hline Mean (SD) & $33.2(84.9)$ & 39.7 (97.9) & $6.6(61.5)$ & 0.436 \\
\hline Median (range) & $0(0,365)$ & $0(0,366)$ & $0(-158,365)$ & \\
\hline
\end{tabular}

Abbreviations: MS, multiple sclerosis; SD, standard deviation.

days were statistically significant for all patients regardless of previous DMT use (Table 2; Table S1). The mean number of MS-related sick days per patient was reduced by 8.0 days $(P<0.001)$ for patients overall, by 7.7 days $(P=0.003)$ for those with prior DMT use, and by 8.9 days $(P=0.012)$ for those without prior DMT use. Similarly, the mean number of all-cause sick days was reduced by 8.3 days $(P<0.001)$, 9.0 days $(P=0.001)$, and 6.2 days $(P=0.026)$, respectively. Both for patients with and without prior DMT use, changes in the proportion of patients with all-cause disability days and in the mean number of all-cause disability days (Table 2; Table S1) were not statistically significant.

\section{Discussion}

Natalizumab has been available in Germany since 2006. ${ }^{30}$ Among German people with MS initiating natalizumab treatment between January 2009 and December 2012 in real-world settings, this study demonstrated significant reductions at 12 months in MS-related and all-cause hospitalizations and corticosteroid use. Administrative medical and pharmacy claims data from the German HRI research database showed that, from the pre- to the post-index period, the proportion of people with MS hospitalized for MS-related and all-cause events decreased by $72 \%$ and $52 \%$, respectively, and the percentage of people with MS using corticosteroids was reduced by $62 \%$. For MS-related and all-cause hospitalizations, per-person costs were reduced by nearly $€ 3,000$; for corticosteroid use, per-person costs were reduced by a mean of approximately $€ 300$. In this study, $75 \%$ of people with MS had used another DMT in the 12 months before starting treatment with natalizumab. The reductions in MS-related and all-cause hospitalizations and costs and MS-related and all-cause sick days were larger among people with MS without prior DMT use. In contrast, reductions in corticosteroid use and disability days were comparable between people with MS with and without prior DMT use. These findings are supported by studies in other countries of people with MS starting or switching to natalizumab. ${ }^{31-33}$ In a similarly designed US-based analysis, significant reductions were observed in MS-related and all-cause hospitalizations, corticosteroid use, and associated costs after starting treatment with natalizumab. ${ }^{31}$ Seventy percent of people with MS had used pre-index DMT; for MS-related hospitalizations and costs, reductions were larger in the cohort of people with MS 

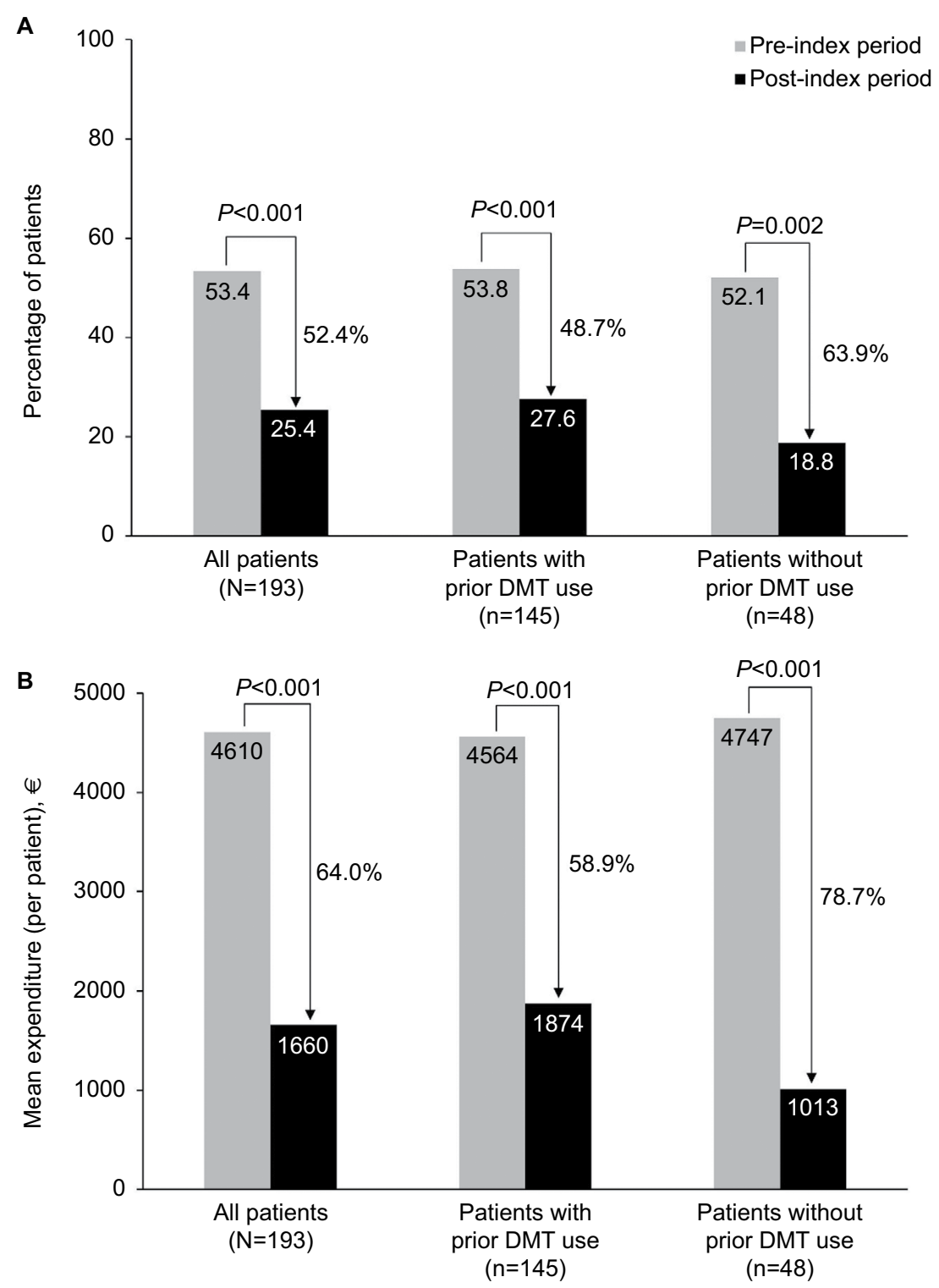

Figure 4 All-cause $(\mathbf{A})$ hospitalizations and $(\mathbf{B})$ inpatient costs. Abbreviation: DMT, disease-modifying therapy.

who had not used pre-index DMT. ${ }^{31}$ In an Italian observational study of people with RRMS who had continued disease activity after interferon beta or glatiramer acetate therapy, a significantly larger percentage of those who switched their therapy to natalizumab showed no evidence of disease activity compared with those who switched to another DMT after 24 months. ${ }^{32}$ In other studies, people with MS with breakthrough disease after the first-line therapy showed larger reductions in disease activity after switching from another DMT to natalizumab. ${ }^{17,33,34}$

In a 2006 German cost-of-illness analysis, the mean total annual cost of MS per person was estimated at $€ 40,000$, twofifths of which was related to decreased productivity owing to sick leave and early retirement. ${ }^{3}$ Decreased numbers of
MS-related sick days (8.0 days) and all-cause sick days (8.3 days) in the first year following natalizumab treatment initiation in this study could correlate with a significant decline in the indirect costs of MS. In combination with the declines in direct medical costs also observed here, the addition of natalizumab to a treatment regimen for a person with MS could have a positive impact on the economic burden of MS in Germany. While decreases in the number of disability-related days were observed, these changes did not reach statistical significance. This may be due to the short 12-month followup period and/or the small number of disabled people with MS. In addition, DMT treatment may mitigate the number of people with MS who become disabled as $70 \%$ of the population is pretreated. Natalizumab significantly reduced 

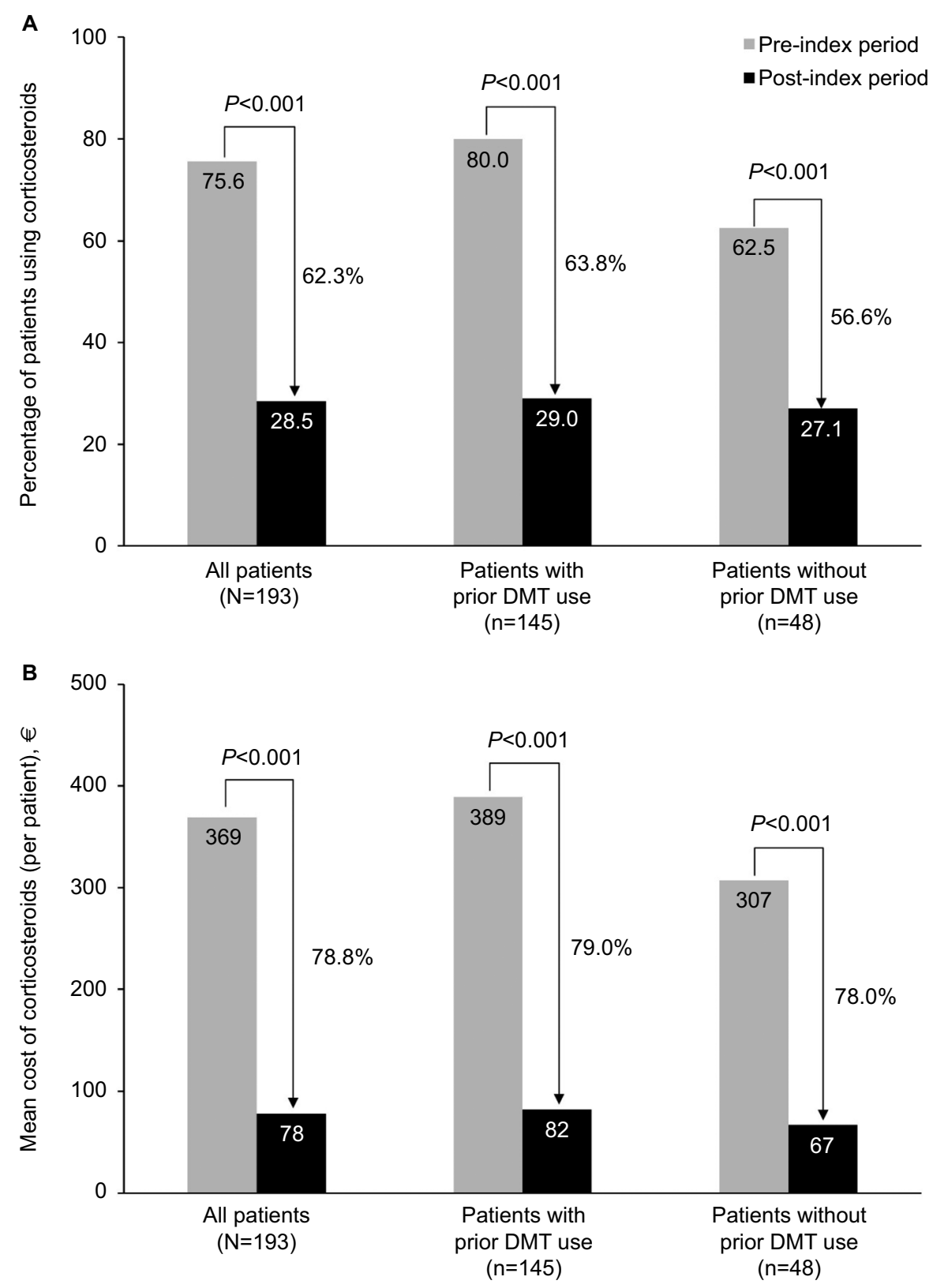

Figure 5 Corticosteroid $(\mathbf{A})$ use and $(\mathbf{B})$ costs. Abbreviation: DMT, disease-modifying therapy.

MS and all-cause HRU and the associated costs. These reductions and cost offsets suggest that natalizumab may be a cost-effective treatment option for MS in Germany.

An analysis of SHI claims data showed that the prevalence of MS in Bavaria had increased by $42 \%$ from 2005 to 2009 , corresponding to an overall projected prevalence of 142,856 people with MS in Germany in 2009. ${ }^{30}$ In addition, the percentage of people with MS receiving $\geq 1$ DMT increased from $46 \%$ in 2005 to $51 \%$ in 2009 . Thus, given the increasing prevalence of MS and the increasing proportion of people with MS receiving multiple DMTs in Germany, the findings from the current study suggest that natalizumab may positively impact the high economic burden associated with HRU among German people with MS. ${ }^{4}$

As this is a descriptive study, these results should be interpreted in the context of certain limitations. First, although the HRI research database is generally representative of the German population, the relatively small sample size of this study restricts the extent to which the findings are generalizable to the German population of people with MS, at large. Furthermore, the study results may not be generalizable to pregnant women, as they were excluded from this analysis. It was not possible to evaluate clinical measures of effectiveness, including disability progression, as typically assessed by 

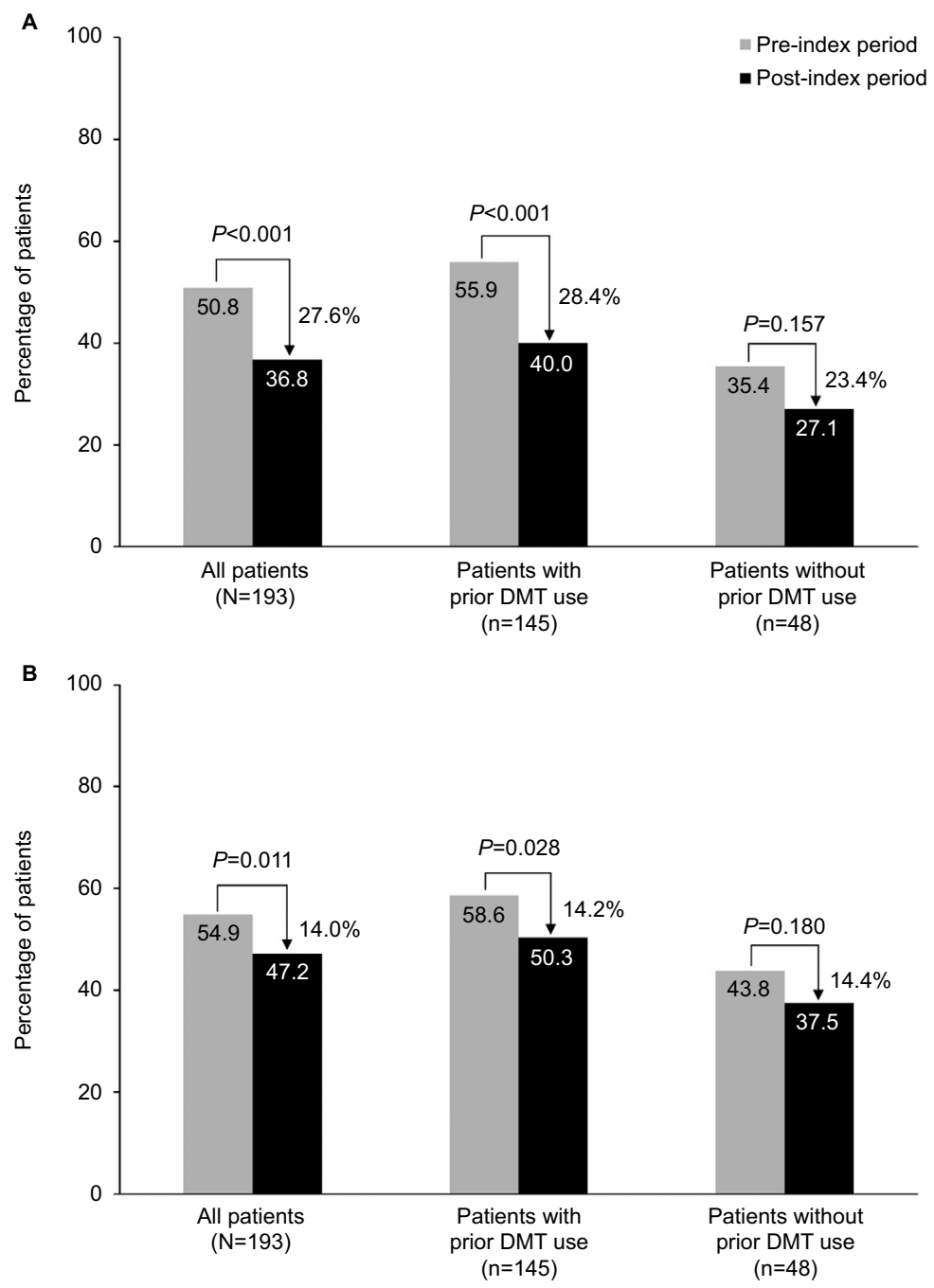

Figure 6 Percentage of patients with (A) multiple sclerosis-related and (B) all-cause sick days.

Abbreviation: DMT, disease-modifying therapy.

changes in Expanded Disability Status Scale scores, clinically identified relapses, and severity of the relapses, as this information is not available from the HRI research database. In addition, the time period of the analysis does not allow for a complete record of a person's history with MS, including disease duration, prior treatment, or relapse, all of which may differ over time. Also, to have a comparable patient sample, only patients staying on natalizumab therapy were included.

These analyses were limited by the 1-year pre- and post-index periods, and future analyses can examine 2-year pre- and post-index periods, provided that sample sizes are large enough. These analyses were also limited to HRU (i.e., hospitalizations, corticosteroid use, and sick days) related to MS outcomes and did not include any DMT costs, such as the cost of natalizumab or DMT costs in the pre-index period. In addition, corticosteroid use may be underestimated in this study because its use in the inpatient setting could not be included in this analysis. Corticosteroid use was evaluated as a dichotomous outcome, and corticosteroid dosing changes around natalizumab were not evaluated. Future research should expand on this issue and describe corticosteroid dosing over time. Finally, in German claims data, outpatient visits are not coded with a diagnosis code, and emergency room (ER) visits cannot be assessed; therefore, MS-specific outpatient visits and ER visits were not included in this analysis.

Further research is warranted, including a more detailed analysis to evaluate study outcomes among people with MS by disease severity and to evaluate hospitalizations that may be preventable, thereby reducing HRU-related costs.

\section{Conclusions}

In a real-world setting in Germany, people with MS who initiated treatment with natalizumab demonstrated significant reductions in MS-related and all-cause inpatient stays and corticosteroid use with associated costs. Natalizumab was also associated with significant decreases from the pre-index period 
in the percentage of people with MS-related and all-cause sick days and in the mean number of MS-related and all-cause sick days. These findings suggest that the benefits of natalizumab, as demonstrated in clinical trials, translate into real-world reductions in MS-related and all-cause hospitalizations and corticosteroid use. In addition, people with MS without DMT use had a greater magnitude of reduction in both MS-related and all-cause inpatient utilization and costs following natalizumab initiation than people with MS with prior DMT use, further highlighting the need to start treatment early.

\section{Acknowledgments}

The study was sponsored by Biogen, and Biogen provided funding for editorial support in the development of this manuscript; Linda A. Goldstein (Infusion Communications, Haddam, CT, USA) wrote the first draft of the manuscript based on input from authors, and Joshua Safran and Melissa Austin (Infusion Communications) copyedited and styled the manuscript per journal requirements. Biogen reviewed and provided feedback on the manuscript to the authors. The authors had full editorial control of the manuscript and provided their final approval of all content.

The data analysis was performed with cooperation from Xcenda and Elsevier Health Analytics.

The abstract of this paper was presented at the ISPOR 20th Annual International Meeting in Philadelphia on May 16-20, 2015, as a poster presentation; the poster's abstract was published in Value Health 2015;18(3):A284; available at http://www.valueinhealthjournal.com/article/S10983015(15)01716-7/abstract?_returnURL=http $\% 3 \mathrm{~A} \% 2 \mathrm{~F} \% 2$ Flinkinghub.elsevier.com $\% 2$ Fretrieve $\% 2$ Fpii $\% 2 F S 109830$ 1515017167\%3Fshowall\%3Dtrue.

\section{Disclosure}

Crystal Watson, Erika Gleissner, and Sarah Naoshy are employees of and hold stock/stock options in Biogen. Christine Prosser, Sebastian Braun, and Pamela B LandsmanBlumberg are employees of Xcenda, which has a research consultancy agreement with Biogen. The authors report no other conflicts of interest in this work.

\section{References}

1. Koch-Henriksen N, Sorensen PS. The changing demographic pattern of multiple sclerosis epidemiology. Lancet Neurol. 2010;9(5):520-532.

2. Flachenecker P, Stuke K, Elias W, et al. Multiple sclerosis registry in Germany: results of the extension phase 2005/2006. Dtsch Arztebl Int. 2008;105(7):113-119.

3. Kobelt G, Berg J, Lindgren P, et al. Costs and quality of life of multiple sclerosis in Germany. Eur J Health Econ. 2006;7(Suppl 2):S34-S44.

4. Reese JP, John A, Wienemann G, et al. Economic burden in a German cohort of patients with multiple sclerosis. Eur Neurol. 2011;66(6): 311-321.
5. Frischer JM, Bramow S, Dal-Bianco A, et al. The relation between inflammation and neurodegeneration in multiple sclerosis brains. Brain. 2009;132(Pt 5):1175-1189.

6. Kappos L, Moeri D, Radue EW, et al. Predictive value of gadoliniumenhanced magnetic resonance imaging for relapse rate and changes in disability or impairment in multiple sclerosis: a meta-analysis. Gadolinium MRI Meta-analysis Group. Lancet. 1999;353(9157):964-969.

7. Miller DH, Grossman RI, Reingold SC, McFarland HF. The role of magnetic resonance techniques in understanding and managing multiple sclerosis. Brain. 1998;121(Pt 1):3-24.

8. Bjartmar C, Kidd G, Mork S, Rudick R, Trapp BD. Neurological disability correlates with spinal cord axonal loss and reduced $\mathrm{N}$-acetyl aspartate in chronic multiple sclerosis patients. Ann Neurol. 2000;48(6):893-901.

9. Compston A, Coles A. Multiple sclerosis. Lancet. 2008;372(9648): $1502-1517$

10. Nickerson M, Cofield SS, Tyry T, Salter AR, Cutter GR, Marrie RA. Impact of multiple sclerosis relapse: the NARCOMS participant perspective. Mult Scler Relat Disord. 2015;4(3):234-240.

11. Weinstock-Guttman B, Galetta SL, Giovannoni G, et al. Additional efficacy endpoints from pivotal natalizumab trials in relapsing-remitting MS. J Neurol. 2012;259(5):898-905.

12. Tyas D, Kerrigan J, Russell N, Nixon R. The distribution of the cost of multiple sclerosis in the UK: how do costs vary by illness severity? Value Health. 2007;10(5):386-389.

13. Bourdette DN, Prochazka AV, Mitchell W, Licari P, Burks J. Health care costs of veterans with multiple sclerosis: implications for the rehabilitation of MS. VA Multiple Sclerosis Rehabilitation Study Group. Arch Phys Med Rehabil. 1993;74(1):26-31.

14. Naci H, Fleurence R, Birt J, Duhig A. Economic burden of multiple sclerosis: a systematic review of the literature. Pharmacoeconomics. 2010;28(5):363-379.

15. Windt R, Glaeske G, Hoffmann F. Treatment of multiple sclerosis in Germany: an analysis based on claims data of more than 30,000 patients. Int J Clin Pharm. 2013;35(6):1229-1235.

16. Polman CH, O'Connor PW, Havrdova E, et al. A randomized, placebocontrolled trial of natalizumab for relapsing multiple sclerosis. $N$ Engl J Med. 2006;354(9):899-910.

17. Spelman T, Kalincik T, Zhang A, et al. Comparative efficacy of switching to natalizumab in active multiple sclerosis. Ann Clin Transl Neurol. 2015;2(4):373-387.

18. Hutchinson M, Kappos L, Calabresi PA, et al. The efficacy of natalizumab in patients with relapsing multiple sclerosis: subgroup analyses of AFFIRM and SENTINEL. J Neurol. 2009;256(3):405-415.

19. Tysabri (natalizumab): Summary of Product Characteristics. Berkshire, UK: Biogen; 2006.

20. GKV-Spitzenverband. Shaping Health Together in Europe: Position Paper by the National Association of Statutory Health Insurance Funds; 2014. Available from: https://www.gkv-spitzenverband.de/media/ dokumente/presse/publikationen/P140184_GKV_PP_Europa_EN_barrierefrei.pdf. Accessed June 29, 2015.

21. GKV-Spitzenverband. Statutory health insurance; 2015. Available from: https://www.gkv-spitzenverband.de/english/statutory_health_insurance/ statutory_health_insurance.jsp. Accessed June 29, 2015.

22. Petersen G, Wittmann R, Arndt V, Gopffarth D. [Epidemiology of multiple sclerosis in Germany: regional differences and drug prescription in the claims data of the statutory health insurance]. Nervenarzt. 2014;85(8):990-998. German.

23. Andersohn F, Walker J. Characteristics and external validity of the German Health Risk Institute (HRI) Database. Pharmacoepidemiol Drug Saf. 2016;25(1):106-109.

24. Statistisches Bundesamt. German population as of December 31, 2011 (based on 2011 census data): gender; 2015. Available from: https://www. destatis.de/EN/FactsFigures/SocietyState/Population/CurrentPopulation/Tables/Census_SexAndCitizenship.html. Accessed July 2, 2015.

25. Statistisches Bundesamt. German population as of December 31, 2011 (based on 2011 census data): population by age group; 2015. Available from: https://www.destatis.de/EN/FactsFigures/SocietyState/Population/CurrentPopulation/Tables_/lrbev01.html. Accessed July 2, 2015. 
26. Deyo RA, Cherkin DC, Ciol MA. Adapting a clinical comorbidity index for use with ICD-9-CM administrative databases. J Clin Epidemiol. 1992;45(6):613-619.

27. Charlson ME, Pompei P, Ales KL, MacKenzie CR. A new method of classifying prognostic comorbidity in longitudinal studies: development and validation. J Chronic Dis. 1987;40(5):373-383.

28. Diener HC, Weimar C. Diagnostik und Therapie der Multiplen Sklerose. Leitlinien für Diagnostik und Therapie in der Neurologie [Diagnostics and therapy of multiple sclerosis. Guidelines for diagnostics and therapy in neurology]. Stuttgart, Germany: Thieme Verlag; 2012. German.

29. Statistisches Bundesamt. Consumer price index and inflation rate; 2013. Available from: https://www.destatis.de/EN/FactsFigures/ NationalEconomyEnvironment/Prices/ConsumerPriceIndices/BasketGoodsServicesWeightingPattern/CPIVideo.html. Accessed June 29, 2015 .
30. Hoer A, Schiffhorst G, Zimmermann A, et al. Multiple sclerosis in Germany: data analysis of administrative prevalence and healthcare delivery in the statutory health system. BMC Health Serv Res. 2014;14:381.

31. Bonafede MM, Johnson BH, Watson C. Health care-resource utilization before and after natalizumab initiation in multiple sclerosis patients in the US. Clinicoecon Outcomes Res. 2013;6:11-20.

32. Prosperini L, Gianni C, Leonardi L, et al. Escalation to natalizumab or switching among immunomodulators in relapsing multiple sclerosis. Mult Scler. 2012;18(1):64-71.

33. Castillo-Trivino T, Mowry EM, Gajofatto A, et al. Switching multiple sclerosis patients with breakthrough disease to second-line therapy. PLoS One. 2011;6(2):e16664.

34. Kalincik T, Horakova D, Spelman T, et al. Switch to natalizumab versus fingolimod in active relapsing-remitting multiple sclerosis. Ann Neurol. 2015;77(3):425-435 


\section{Supplementary material}

Table SI Health care resource utilization among the subgroups of patients with and without prior DMT use before and after initiating treatment with natalizumab

\begin{tabular}{|c|c|c|c|c|c|c|c|c|}
\hline \multirow{2}{*}{$\begin{array}{l}\text { Health care } \\
\text { resource utilization }\end{array}$} & \multicolumn{4}{|c|}{ Patients with prior DMT use $(n=\mid 45)$} & \multicolumn{4}{|c|}{ Patients without prior DMT use $(n=48)$} \\
\hline & Pre-index & Post-index & Change & $P$-value & Pre-index & Post-index & Change & $P$-value \\
\hline \multicolumn{9}{|c|}{ Number of hospitalizations } \\
\hline \multicolumn{9}{|c|}{ MS-related } \\
\hline Mean (SD) & I.I (I.5) & $0.2(0.7)$ & $-0.9(1.4)$ & $<0.001$ & $0.9(1.3)$ & $0.1(0.4)$ & $-0.8(1.2)$ & $<0.001$ \\
\hline Median (range) & $\mathrm{I}(0,8)$ & $0(0,5)$ & $0(-6,3)$ & & $0(0,5)$ & $0(0,2)$ & $0(-4,1)$ & \\
\hline \multicolumn{9}{|l|}{ All-cause } \\
\hline Mean (SD) & $1.4(1.8)$ & $0.50(1.3)$ & $-0.9(1.8)$ & $<0.001$ & $1.2(1.7)$ & $0.3(0.6)$ & $-1.0(1.7)$ & $<0.001$ \\
\hline Median (range) & $\mathrm{I}(0,9)$ & $0(0,11)$ & $0(-7,9)$ & & $\mathrm{I}(0,8)$ & $0(0,3)$ & $-0.5(-8,2)$ & \\
\hline \multicolumn{9}{|c|}{ Number of inpatient days } \\
\hline \multicolumn{9}{|c|}{ MS-related } \\
\hline Mean (SD) & $7.2(11.2)$ & $3.4(23.5)$ & $-3.8(23.2)$ & $<0.001$ & $6.3(9.3)$ & $0.6(2.1)$ & $-5.7(8.6)$ & $<0.001$ \\
\hline Median (range) & $4(0,62)$ & $0(0,277)$ & $0(-62,238)$ & & $0(0,36)$ & $0(0,13)$ & $0(-35,2)$ & \\
\hline \multicolumn{9}{|l|}{ All-cause } \\
\hline Mean (SD) & $9.8(16.0)$ & $5.6(25.6)$ & $-4.1(25.2)$ & $<0.001$ & $9.2(18.4)$ & $3.0(15.3)$ & $-6.2(24.5)$ & $<0.001$ \\
\hline Median (range) & $4(0,104)$ & $0(0,277)$ & $0(-66,238)$ & & $1.5(0,113)$ & $0(0,105)$ & $-1.5(-113,105)$ & \\
\hline \multicolumn{9}{|l|}{ Corticosteroid use } \\
\hline Mean (SD) & $2.6(2.5)$ & $0.5(1.0)$ & $-2.0(2.4)$ & $<0.001$ & $2.1(2.4)$ & $0.9(1.9)$ & $-1.2(2.1)$ & $<0.001$ \\
\hline Median (range) & $2(0,19)$ & $0(0,4)$ & $-2(-19,3)$ & & $\mathrm{I}(0,10)$ & $0(0,8)$ & $-0.5(-7,3)$ & \\
\hline \multicolumn{9}{|l|}{ Number of sick days } \\
\hline \multicolumn{9}{|l|}{ MS-related } \\
\hline Mean (SD) & $32.6(55.5)$ & $24.9(6 \mid .2)$ & $-7.7(65.2)$ & 0.003 & $21.4(44.5)$ & $12.5(33.8)$ & $-8.9(39.0)$ & 0.012 \\
\hline Median (range) & $4(0,326)$ & $0(0,366)$ & $0(-308,3 I I)$ & & $0(0,209)$ & $0(0,165)$ & $0(-162,146)$ & \\
\hline \multicolumn{9}{|l|}{ All-cause } \\
\hline Mean (SD) & $39.4(61.1)$ & $30.4(64.5)$ & $-9.0(66.3)$ & 0.001 & $26.7(49.5)$ & $20.5(50.8)$ & $-6.2(56.1)$ & 0.026 \\
\hline Median (range) & $10(0,330)$ & $\mathrm{I}(0,366)$ & $0(-3 \mid 2,256)$ & & $0(0,2 \mid 3)$ & $0(0,270)$ & $0(-166,249)$ & \\
\hline \multicolumn{9}{|c|}{ Number of all-cause disability days } \\
\hline Mean (SD) & $37.8(90.9)$ & $45.7(105.5)$ & $7.9(65.1)$ & 0.386 & $19.1(61.9)$ & $21.7(68.0)$ & $2.6(49.1)$ & 1.000 \\
\hline Median (range) & $0(0,365)$ & $0(0,366)$ & $0(-158,365)$ & & $0(0,365)$ & $0(0,366)$ & $0(-123,249)$ & \\
\hline
\end{tabular}

Abbreviations: DMT, disease-modifying therapy; MS, multiple sclerosis; SD, standard deviation.

ClinicoEconomics and Outcomes Research

\section{Publish your work in this journal}

ClinicoEconomics and Outcomes Research is an international, peerreviewed open-access journal focusing on health technology assessment, pharmacoeconomics and outcomes research in the areas of diagnosis, medical devices, and clinical, surgical and pharmacological intervention. The economic impact of health policy and health systems
Submit your manuscript here: https://www.dovepress.com/clinicoeconomics-and-outcomes-research-journal

organization also constitute important areas of coverage. The manuscript management system is completely online and includes a very quick and fair peer-review system, which is all easy to use. Visit http://www.dovepress.com/testimonials.php to read real quotes from published authors. 